\title{
The dynamic specificity of interlingual interference within the context of virtual space: towards the theoretical framework of the phenomenon (by the example of political discourse)
}

\author{
Sergey Nikolaev and Emil Sarkisov* \\ Southern Federal University, Rostov-on-Don, 344000, Russia
}

\begin{abstract}
This paper deals with the problem of interference within the context of language convergence in virtual space. The study aims to analyze in detail the role of virtual space communication as a new favorable environment for interferential processes not just on the structural level, on the conceptual level too, since deviation from language norms as a serving instrument in terms of formation of the linguistic picture of the world results in changing the way one conceptualizes reality. The major research methods are contrastive analysis and conceptual analysis. The practical significance of the research is determined by the fact that its results can be used in the educational process, for example, when teaching various courses in intercultural communication, political psychology, sociology, cultural and contact linguistics, (foreign) language teaching, cross-cultural pragmatics, etc. The authors come to a conclusion that significant modifications on the conceptual level occur due to language contacts intensification and because of a stable interference pattern in speech and affect communicants' behavior. This in turn leads to conceptual transformation in language and, as a result, in the way of thinking. The most significant manifestation of this phenomenon can be seen in the political life of the society.
\end{abstract}

\section{Introduction}

Cognitive science in general and cognitive linguistics in particular inevitably touch and constantly interact with other areas of human knowledge, one way or another connected with the most important mental processes in human life such as thinking, cognition and speech. Rapid development of cognitive linguistics makes it possible to take a new look at the phenomena that determine various spheres of interpersonal and man-society interaction [1]. The issue acquires special relevance against the background of deepening processes of globalization and the accompanying technological development that promotes them. It must be admitted that a significant factor in this case is the emergence of a qualitatively new

\footnotetext{
*Corresponding author: sarkisov@sfedu.ru
} 
form of global communication named virtual space communication [2]. "Global communication" means here not only international and interethnic, but also interlingual communication which naturally leads to interlingual interference.

As interlingual interference arises in a bilingual environment [3], an important feature of virtual space communication is fundamental bilingualism and multilingualism [4], the result of language contacts, which are considered in this research paper as one of the most stable factors accompanying the process of interaction between the government and the society.

Political discourse makes a certain and very significant part of virtual space communication, and "the values of political discourse are reduced to justifying and defending one's right to power" [5]. Political discourse, like any other, is speech viewed as a purposeful social act, often centered on a certain basic concept and creating a general context and reflecting reality: people, objects, conditions, times, behavior, etc. It implements the main purpose of political communication, which is struggle for power [6]. Political discourse reflects both the mentality and culture of the society, and the psychology of the individual, i.e. the politician; proximity of this reflection leads to successful implementation of its purpose. Thus, political discourse is not only a stream of speech in its pure form, but also its permanent appeal to extralinguistic factors. The constant change and development of language caused by the phenomena of interlingual interference therefore determines the political discourse.

One of the main concepts in the paradigm of the theory of language contacts is that of interlingual interference. If 20-25 years ago virtual space communication existed mainly in a written (text) form, today this form has become predominantly oral and written, which further brings it closer to spontaneous, unprepared unmediated communication.

The basic characteristics that make virtual communication so favorable for interlingual interference are its globality and interactivity. The former is associated with a wide territorial coverage due to ubiquitous, universal technologization. The latter, being based on two-way communication between users, allows to enter into direct dialogue both online and offline. Thus, virtual space should be considered as a new polylingual cognitive environment, in which there is a clash of linguocultures, naturally reflected in various national languages.

The current state of the problem of interlingual interference requires an analysis of not only the structural elements of a language, but also their reflection in the system of out-oflanguage associations [7]; therefore, this study will focus on interference as a source of interpenetration of such associative systems in virtualized conditions of language contacts, specifically — within the framework of political discourse, as this historically stable discursive variety can be considered as a tool for the formation of favorable attitudes from the point of view of the political elite. The latter is constantly striving to control political institutions and the mechanisms of power relations.

The concept of interlingual interference became applicable along with the development of the theory of language contacts. The convergence of languages, which is inherent in all types of language contacts and is another source of interlingual interference, is evidently manifested at all levels of the language system. The clearest example of this process in real communication can be observed in Russia, China, the USA, and other countries. Despite this, virtual space deserves no less, perhaps even more attention as an ideal communicative environment for this kind of contacts.

The concepts of interlingual interference and language contacts, regardless of their environment (real or virtual), are interrelated, which fact is clearly reflected in the definitions of various researchers. Among the early studies in the theory of language contacts, it is typical to mention the works by Baudouin de Courtenay and Lev Shcherba. Their conclusions significantly influenced the development of this doctrine. Shcherba defines language contacts as a process consisting in the creation of a general system of 
associative links and the loss of differential features of concepts while maintaining denotative differences; the flow of this process is due to the typology of bilingualism [8]. Based on this thesis, we can conclude that the problem of language contacts is associated with the processes of convergence of the elements of languages and interference, whose essence can be defined as "the influence of one language system on another during the mutual adaptation of language $A$ and language $B$, which leads to norm deviations of both languages in contact" [9]. This definition combines structural, communicative and conceptual approaches when considering norms, since it contains the abstract concept of "element". Its use implies a variable interpretation of the concept of interlingual interference as a whole, as well as the concept of a "system of associations", which suggests considering the phenomenon of language contacts without a strict dependence on the denotative aspect of the sign.

Having previously stipulated the cognitive approach to investigate interlingual interference, we must add here that mixing of systems as one of the interlingual interference types also inevitably occurs at the conceptual level, which, however, is directly related to the purely structural lexical-semantic level. In lexicology this kind of interference is called transfer and there are metaphorical, metonymic and functional types [10]. However, the concept of "interference" arose at the border of scientific knowledge, and what is called transference in lexicology is interpreted in psycholinguistics much more broadly. Mixing at the extralinguistic level is taking place not within the framework of a language system, but through it and in the system of associations, which is, among other things, a set of conceptual norms of a given linguocultural community.

In the field of intercultural communication, intercultural transfer is also distinguished. The authorship of the term belongs to the scientists M. Michel Espagne and Michael Werner, who studied intercultural contacts between Germany and France in 1980. According to Matthias Middell, intercultural transfer is the movement of material objects, people and ideas between two distinct cultures [11]. Here we also see grounds to talk about interference, since different linguocultural backgrounds with their proper conceptual norms coexist.

Consequently, interlingual and conceptual interference are interconnected by systemassociative relations, for a concept is a minimum unit for constructing a linguistic picture of the world, within which language-thinking-connection with the surrounding reality, cultural and ethnic phenomena, as well as directly with interlingual phenomena, is carried out.

Looking at the relation of the above discussed to today's conditions, the beginning of the 21 st century was marked by rapid processes of technological development, economic integration, strengthening of the role of "new" media in the life of the society and a new configuration in the alignment of potentials in the interaction between the government and society. These processes have changed the approach to considering a person in the context of receiving, storing and transmitting information, and when studying this problem, an even wider range of scientific information is now used. This approach is logical, since the current dynamics of individual and social evolution also has its opposite effect, determining the life of the individual and the society. It resulted in the expansion of everyday and scientific experience boundaries, the emergence of a need to search for new factors in the development of civilization and "pushing" the human being into a new virtual space of communication.

Interlingual interference on such a scale is changing the approach to the study of language contacts, which are now viewed as a multifaceted phenomenon that requires pooling of efforts of representatives of related sciences: psychology, sociology, cognitive science, computer and communication sciences, etc. And this is quite logical. The matter is that all of the above phenomena determine human life in modern society and, as a result, the processes that determine the development of languages. Language contacts share with 
its versatility with virtual space communication, which can be defined as perceptuallinguistic interaction associated with acts of cognition and the creation of meaning-forming systems manifesting itself in a whole set of principles, namely:

1) dialogism and communicativeness;

2) visual-perceptual experience;

3) interpersonal communication;

4) a tool for cross-cultural dialogue;

5) linguistic component.

Some of the points, assuming the presence of language contacts, radically distinguish virtual space communication from other types of information transfer.

The virtual space communication of today is a cognitive environment for selforganization and accumulation of new knowledge as a reflection of reality and, therefore, a product of limitless social and cultural traditions, for establishing relations between communicants.

\section{Materials and Mthods}

The functioning of languages in the existing special bilingual communicative environment through the transfer of information by digital channels undoubtedly leads to a need to reconsider the methodology of linguistic research and invites a study of languages both in relation to the environment in which they coexist and those bilinguals speaking the said languages. This circumstance is a good reason for restructuring not only the paradigm of the theory of language contacts, but also, in part, the linguistic theory as a whole.

The main research methods are contrastive analysis [12] and conceptual analysis [13]. This combination of methods is used to identify interference traces at the conceptual level, whose existence is due to the bilingual environment of the virtual space. A contrastive analysis of the elements of bilingual discourse in the virtual space allows to reveal the similarities and differences in the norms of the lexical-semantic level of different languages involved in order to establish the possibility of the presence of interference elements, since the source of interlingual interference is precisely the divergence of the norms of different languages. A conceptual analysis of these differences provides ample opportunities for the interpretation of data obtained in the contrastive analysis of the lexical-semantic level. The object of the research can be defined as the concepts related to the political discourse.

\section{Results}

Even before the first results of the research were obtained, the question immediately arose: how are the incoming conceptual norms of the source language of interference, which do not have a substantial similarity with the conceptual norms of the target language of interference, consolidate in the target language of interference? In fact, this problem is relevant in the light of intralingual interference.

Those concepts that exist in the conceptual system itself and are manifested in linguistic data, structure our perception, our thinking and our actions. The mentioned linguistic data may have the form of utterances which, like any speech act, vary cross-culturally. Representatives of different ethnic groups, nations and cultures sometimes have cardinally different ideas about the same objects and phenomena of the surrounding reality. This is due to the fact that concepts are mental formations that are associated with the culturalhistorical paradigm and include not only objective data, but also evaluative, historical and socio-cultural characteristics of the reflected objects or reality phenomena. For example, the concept "power is strength" (based on the utterance "Opinion polls put the combined 
strength of the two ecology parties at $15 \%$ nationwide") can lead to the one "strength is a new land", which is inconsistent with the modern cultural and value foundations of Western European society, for which technological growth and economic potential are a priority, but find support in the more archaic Asian worldview. Consequently, the interference of the conceptual norm "power is economic / technological growth" derived from the concept "power is a choice" (proper to the Western European society) will not be beneficial for the authorities, whose goal is to win the loyalty of society through promoting the wellestablished conceptual norm "power is a new land".

The latter norm can become part of the conceptual norm of the target language of interference if it takes a place among the stable elements of the interference pattern of the given language. It is the "new" media that exist in virtual space that make it possible to give stability to one or another conceptual norm in the interference pattern.

Among the basic concepts for political discourse there is the concept "political leader". In the mass consciousness of a liberal democratic society (a society of the Western European type), it is associated with a choice: "a leader is a choice", and choice presupposes options. This principle is so ingrained in the conceptual memory of the Western European society that it is impossible to imagine life without choosing a political leader.

In Asian language communities, this is generally not the case. In states with underdeveloped democratic institutions, even if there is a choice, it essentially has little to do with the concept "a leader is a choice". The mentioned conceptual norm of "democratic" languages has not yet been consolidated in the languages of the Asian continent. This is also the case, for example, of the Russian language, where the leader is "gosudar" (gifted by the Lord). Of course, we are talking here about archaic consciousness, but after all, it is this that lays the foundation on which Russian society has been built.

Note that the semantic equivalent of the lexeme gosudar in European languages are señor (Spanish), signor (Italian), Sire (French), Sir (English), etc., which are now used in the respective languages as a polite form address, thereby indicating the equality between the archaic and the modern referents. Moreover, this semantic equality indicates that anyone can become a "political leader", not just those who are "gifted by Lord". The latter circumstance is of special importance due to the fact that the listed signs (señor, signor, Sire) are used and have been used to denote God. From this one can deduce another concept characteristic of Western European society: "Power is respect for the rights of everyone" (not just for the rights of the leader). This outcome was facilitated by intensive language contacts between the peoples of the Western European culture.

Interferential interaction of the languages of virtual space communication within political discourse practices leads to the emergence of such concepts as "an individual is a user", therefore, "power is a service", and "a political leader is a servant". An example of such an end to the "logical" chain can be found in the name of the party whose leader won with a great advantage in the elections in Ukraine - "Servant of the People".

Table 1. The dynamic force presence of the analyzed concepts depending on the society.

\begin{tabular}{|c|c|c|c|}
\hline Concept & $\begin{array}{c}\text { Western European } \\
\text { society }\end{array}$ & $\begin{array}{c}\text { Asian } \\
\text { society }\end{array}$ & $\begin{array}{c}\text { Virtual space } \\
\text { society } \\
\text { (potentially) }\end{array}$ \\
\hline Power is strength & $\checkmark$ & $\checkmark$ & $\checkmark$ \\
\hline Power is a new land & X & $\checkmark$ & $\checkmark$ \\
\hline Power is economic / technological growth & $\checkmark$ & X & $\checkmark$ \\
\hline Power is a choice & $\checkmark$ & X & $\checkmark$ \\
\hline Power is respect for the rights of everyone & $\checkmark$ & X & $\checkmark$ \\
\hline
\end{tabular}


In the formation of an individual's picture of the world, as well as one of society, not only the elements originally inherent in the previously created sense-forming fund are in an active position, but also those concepts specific to multilingual virtual space communication and their corresponding terms that penetrate the mentality and culture of a people. It should be noted that the extension of the latter is easier, since they are not characteristic of the conceptual picture of the world of a particular national-cultural community, which means that they do not find a counterbalance when representatives of other national-cultural communities are involved in their identity. In addition, such elements are so often used by speakers that they soon become part of a stable interference pattern of the object language of interference. For example, the term user in Russian even exists in the form of the morphological calque "user".

Thus, virtual space is a unique social phenomenon that forms a cognitive system different from the previous one, a system of value-oriented attitudes. Interlingual interference characteristic of it has a dynamic nature, that is, it affects the behavior of virtual space communicants.

\section{Discussion}

The dynamic nature of interference could not but affect the phenomenon of communication. It has changed, if not in essence, then in the form of embodiment [14], like all the side processes. First of all, virtual space communication should be considered as inherent in real-life communication, since any of its varieties exists in both practical and ideal terms. Both spaces, which have long existed in parallel in the mind of real-life and virtual communication participants, inevitably interact with each other, affecting the process of communication itself. Such an interaction results in a gradual boundaries blurring between the two spaces, which is a consequence of the constant increase in the volume of information transmitted through digital channels, which the individual is logically unable to process.

From this point of view, restrictions on a full-fledged access to virtual space by the political elite are justified, since the smaller the number of identifications in which a representative of a given society is involved, the less likely it is to lose its loyalty. Identification here can be defined as agreement and acceptance of the semantic content of conceptual norms.

The national-conceptual norm is stable and free from the influence of communication in virtual space, it is considered as constant; the national-conceptual norm in a free virtual space is characterized by mutability and variability

As for politics as an independent sphere of human activity, its goal in the Western European society of today can be considered as finding an effective algorithm for domination in order to win the political loyalty of society. In this mechanism, the media has the mediating function of ideological control over the mass consciousness [15]. The successful result of these relations can be considered such an influence when the picture of the world demanded by the authorities is built (as a rule, far from objective).

It should be noted that such relations prevail in the societies that are far from capitalism and its inherent liberal principles. In the societies of this kind, the authorities put up all sorts of obstacles to full access to virtual space communication as an alternative source of information in virtual space, not so much because of the fear that society will gain access to objective information, but because of interference influence on the conceptual norms of a certain linguistic community.

In a state in which the government promotes or at least does not hinder the development of virtual space or real space with language contacts, interference on the conceptual level 
inevitably occurs. In a state where the government in every possible way retards the development or restricts access to virtual space or real space with language contacts that provide conceptual interference of different pictures of the world, an intra-linguistic conceptualization of reality takes place, since the ideas adopted for constructing a conceptual picture of the world have either already become universal or are only characteristic of a given ethnolinguocultural code.

In the future, this phenomenon is of interest from different sides. For example, the constant transition from one conceptual norm to another indicates an individual's attempt to adapt to changing environmental conditions, developing the adaptive function of the psyche. As for the interpenetration of elements of various conceptual pictures of the world, this process also contributes to the development of thinking flexibility, because interference at the conceptual level allows to improve the mechanisms of transmission and transformation of ideas. At the same time, the processes of thinking are interconnected with speech and, therefore, with language.

\section{Conclusions}

Virtual space communication makes a significant contribution to the development of language contacts and, consequently, interlingual interference, which leads to deviations from the norm not only in language, but also at the verbal-thinking and socio-cultural levels, thus changing the conceptual norms of individuals and society. Interference processes of such a type lead to transformation in the perception of political discourse.

Language contacts and the adjacent phenomenon of interlingual interference under conditions of modern virtual space communication will only intensify, and the role of languages secondary to English will grow, which means that idioms like lingua franca will undergo changes not only at the structural, but also at the conceptual level. They are able to function as bearers of unique spiritual values of both national and universal culture. In general, the listed processes correspond to the spirit of globalization.

The reported study was funded by RFBR, project number 20-312-90057.

\section{References}

1. X. Wen, K. Yang, F. Kuang, Cognitive Linguistic Studies 1(2), 155-170 (2014)

2. A. Borcuch, M. Piłat-Borcuch, U. Świerczyńska-Kaczor, Journal of Economics and Business Research 1 (18), 118-129 (2012)

3. S.G. Nikolaev, Southern Federal University Press, Rostov on Don. 72-82 (2019)

4. B. Danet, S.C. Herring, Journal of Computer-Mediated Communication 1(9), JCMC9110 (2003)

5. V.I. Karasik, Language circle: personality, concepts, discourse (Peremena, Volgograd, 2002).

6. L. Sankar, International Journal of Academic Research. 5(4), 520-527 (2013)

7. E.E. Sarkisov, Proceedings of Southern Federal University, Philology 3, 58-66 (2020)

8. L.V. Shcherba, Selected works in linguistics and phonetics (Leningrad University Press, Leningrad, 1958)

9. H. Bussmann, Routledge Dictionary of Language and Linguistics (1st edn. Routledge, London \& New York, 1996). 
10. A.V. Pavlova, The theory of language and intercultural communication 2(6), 62-64 (2009)

11. J. Gienow-Hecht, F. Schumacher, Culture and International Histoiy (1st edn. Berghahn Books, Oxford, New York, 2004).

12. C.R. James, Contrastive Analysis (1st edn. Routledge, London, 1980).

13. G Lakoff, M. Johnson, Metaphors We Live by (1st edition. University of Chicago Press, Chicago, 1980).

14. E.E. Sarkisov, Scientific Thought of the Caucasus 1(97), 83-89 (2019)

15. V.V. Kikhtan, V.N. Tatishchev bulletin of the Volga University 2(2), 221-227 (2018) 